\title{
BMJ Open Monitoring air pollution effects on children for supporting public health policy: the protocol of the prospective cohort MAPEC study
}

\author{
D Feretti, ${ }^{1}$ E Ceretti, ${ }^{1}$ A De Donno, ${ }^{2}$ M Moretti, ${ }^{3}$ A Carducci, ${ }^{4}$ S Bonetta, ${ }^{5}$ \\ M R Marrese, ${ }^{6}$ A Bonetti, ${ }^{7}$ L Covolo, ${ }^{1} \mathrm{~F}$ Bagordo, ${ }^{2} \mathrm{M}$ Villarini, ${ }^{3} \mathrm{M}$ Verani, ${ }^{4}$ \\ T Schilirò, ${ }^{5}$ R M Limina,${ }^{1}$ T Grassi, ${ }^{2}$ S Monarca ${ }^{3}$ B Casini, ${ }^{8}$ E Carraro, ${ }^{5}$ C Zani, ${ }^{1}$ \\ G Mazzoleni, ${ }^{9}$ R Levaggi, ${ }^{10} \mathrm{U}$ Gelatti, ${ }^{1}$ the MAPEC_LIFE Study Group
}

To cite: Feretti D, Ceretti E, De Donno A, et al. Monitoring air pollution effects on children for supporting public health policy: the protocol of the prospective cohort MAPEC study. BMJ Open 2014;4: e006096. doi:10.1136/ bmjopen-2014-006096

- Prepublication history for this paper is available online. To view these files please visit the journal online (http://dx.doi.org/10.1136/ bmjopen-2014-006096).

Received 11 July 2014 Revised 8 August 2014 Accepted 11 August 2014

CrossMark

For numbered affiliations see end of article.

Correspondence to Dr D Feretti; donatella. feretti@unibs.it

\section{ABSTRACT}

Introduction: Genotoxic biomarkers have been studied largely in adult population, but few studies so far have investigated them in children exposed to air pollution. Children are a high-risk group as regards the health effects of air pollution and some studies suggest that early exposure during childhood can play an important role in the development of chronic diseases in adulthood. The objective of the project is to evaluate the associations between the concentration of urban air pollutants and biomarkers of early biological effect in children, and to propose a model for estimating the global risk of early biological effects due to air pollutants and other factors in children.

Methods and analysis: Two biomarkers of early biological effects, DNA damage by the comet assay and the micronuclei (MN) test, will be investigated in oral mucosa cells of 6-8-year-old children. Concurrently, some toxic airborne pollutants (polycyclic aromatic hydrocarbon (PAH) and nitro-PAH) and in vitro air mutagenicity and toxicity in ultra-fine air particulates (PM0.5) will be evaluated. Furthermore, demographic and socioeconomic variables, other sources of exposures to air pollutants and lifestyle variables will be assessed by a structured questionnaire. The associations between sociodemographic, environmental and other exposure variables and biomarkers of early biological effect using univariate and multivariate models will be analysed. A tentative model for calculating the global absolute risk of having early biological effects caused by air pollution and other variables will be proposed.

Ethics and dissemination: The project has been approved by the Ethics Committees of the local Health Authorities. The results will be communicated to local Public Health Agencies, for supporting educational programmes and health policy strategies. LIFE+2012 Environment Policy and Governance. LIFE12 ENV/IT/ 000614.

\section{INTRODUCTION}

Air pollution is a global problem, especially in urban areas. ${ }^{1}$ In particular, particulate matter (PM) has been studied intensely as

\section{Strengths and limitations of this study}

This project has some strengths compared with previous studies on the effects of air pollution on human health:

- Direct measures of air pollution exposure using data on daily concentration of fine particulate matter, including PM10 and PM2.5, nitrogen dioxide, ozone, carbon monoxide, sulfur dioxide and benzene and evaluation of toxicity and mutagenicity of urban air using in vitro mutagenicity and toxicity tests on PM0.5 extracts;

- Direct measures of biological effect in buccal mucosa cells of 1000 children enrolled in various areas and in two different seasons, that is, MN frequency and DNA damage, which have been shown to be predictive of cancer development later in life.

The main limitations of this study are:

- The biomarkers examined are not specific, as DNA damage can be caused by numerous environmental and individual (genetic and metabolic) factors:

- Weather conditions not suitable for air sampling (rain, snow, strong wind) may be a limit but there is nothing that can be done about it.

regards its effects on human health. PM consists of breathable particles to which several compounds, such as heavy metals, polycyclic aromatic hydrocarbons (PAHs) and some volatile compounds, may adhere. Epidemiological studies have found a consistent association between exposure to airborne PM and incidence and mortality for cardiovascular disease and lung cancer and naturalcause mortality. ${ }^{2-9}$ Recently, also diabetes and other chronic diseases have been associated with PM exposure, possibly through oxidative stress and inflammation. ${ }^{10}$

The finest fractions of PM (PM with aerodynamic diameter $<2.5 \mu \mathrm{m}$ and less) play a 
major role in causing chronic diseases because they are retained in the alveolar regions of the lung and diffuse into the blood stream, inducing inflammation, oxidative stress and blood coagulation. ${ }^{71-13}$ Extracts of urban air particles can induce cancer in animals, ${ }^{14}{ }^{15}$ and are mutagenic in bacteria, plant and mammalian cells in in vitro tests. ${ }^{16-22}$

Urban air is a complex and variable mixture of many different chemical species. ${ }^{123}$ The effects of exposure to such a mixture are not merely the sum of the effects of each compound, because they can interact with synergistic effects; moreover, one or more chemicals can cause different effects and have multiple cellular targets. ${ }^{24}$ It has been reported that even moderate or low levels of air pollution can contribute to carcinogenesis. ${ }^{7} 23$ Indeed, due to the very large number of people exposed to air pollutants, even a small increase in the risk of disease is a relevant public health issue.

Among the several adverse health effects associated with exposure to air pollutants, genetic damage has received a particular interest, especially because a high frequency of markers of chromosomal damage, such as chromosomal aberrations and micronuclei (MN) in peripheral blood lymphocytes, has been found to predict cancer occurrence in cohort studies. ${ }^{25-27}$

Genetic biomarkers have been studied largely in adult population, but only few studies so far have investigated genetic damage in children exposed to air pollution. ${ }^{27-31}$

In recent years $\mathrm{MN}$ frequency in buccal mucosa (BM) cells of children or young adults has been studied showing cytogenetic damage in participants who lived in areas with high concentration of PM or oxidant pollutants. $^{32-37}$

Recently, Ceretti $e t a l^{37}$ found a higher MN frequency than that observed in a pooled general population of the same age ${ }^{27}$ in exfoliated buccal cells of preschool children living in a highly polluted town in the Po Valley in Italy.

On the other hand, studies of genetic damage in children are of the utmost interest because children are a high-risk group as regards the short-term and long-term health effects of air pollution. ${ }^{38-43}$ Indeed, some studies suggest that early exposure during childhood can play an important role in the development of chronic diseases in adulthood: the earlier the exposure, the greater the risk of chronic disease, including cancer. ${ }^{44}$

The MN test is a mutagenicity test widely used as a marker of early biological effects due to its ability to detect both clastogens and aneuploidy-inducing chemicals. ${ }^{45} \mathrm{MN}$ appear in the cytoplasm of interphasic cells as small additional nuclei, smaller than main nuclei. They are formed of acentric chromosomal fragments or whole chromosomes that are not included in the main daughter nuclei during nuclear division. $\mathrm{MN}$ induction therefore reflects clastogenic and/or aneugenic events.

The primary DNA damage may be studied also using the comet assay (single cell gel electrophoresis test), which is one of the genotoxicity tests that rapidly detects
DNA damage in eukaryotic cells. In alkaline conditions, it detects single-stranded and double-stranded breaks, alkali labile sites, incomplete repair sites and possibly also DNA-DNA and DNA-protein cross-links. The comet test shows very early, reversible DNA damage that represents a marker of early biological effect. ${ }^{46-49}$

The MN frequency and the primary DNA damage, as markers of early biological effect, may be studied in different types of cells, such as lymphocytes and exfoliated cells from nasal and BM, and from urine. ${ }^{30} 49$ Buccal cells are certainly easier to collect than blood and do not require highly trained personnel. Moreover, collection of BM cells is considered more acceptable to children and therefore more useful in studies on the paediatric population.

The main objective of the project is to analyse the associations between some air pollution parameters (PM10, PM2.5, PM0.5, NOx, PAHs and nitro-PAHs) and two biomarkers of early effect, and to propose a model for estimating the global risk of early biological effects due to air pollutants and other factors including demographic and socioeconomic factors, indoor exposures, diet, physical activity, body mass index (BMI) in school children. These data will provide information valuable for guiding policy-making and planning individual and community interventions to protect children from possible health effects of air pollutants. This objective will be achieved studying two biomarkers of DNA damage, the comet assay and the frequency of $\mathrm{MN}$, in oral mucosa cells of 6-8-year-old children, and the following exposure variables, as possible risk factors: airborne pollutants, in vitro air mutagenicity and toxicity, exposures to other indoor/outdoor pollutants, demographic and socioeconomic variables, and lifestyle variables. The project will also be useful for increasing the sensitivity of people to air pollution concerns and promote the local authorities' involvement in efforts to reduce urban air pollutants.

\section{METHODS AND ANALYSIS}

\section{Study design}

The MAPEC project runs 3 years (2014-2016). The core of the study is a prospective epidemiological cohort study to evaluate and disseminate a method for monitoring biological effects of air pollution on children, with regard to biological parameters that can predict the occurrence of chronic diseases in adult age. Markers of early biological effect, such as primary DNA damage evaluated with the comet assay and presence of $\mathrm{MN}$, will be investigated in BM cells taken from 6-8-year-old children living in five Italian towns (Brescia, Turin, Pisa, Perugia and Lecce), with different levels of airborne particulates (PM10 annual average from $44 \mu \mathrm{g} / \mathrm{m}^{3}$ measured in Torino to $20 \mu \mathrm{g} / \mathrm{m}^{3}$ measured in Lecce).$^{50}$ Child exposure to urban air pollution will be evaluated by collecting ultra-fine PM (PM0.5) samples in the school areas, on the same day of biological sampling. 
The particulate samples will be analysed for PAH and nitro-PAH concentration and for in vitro toxicity and mutagenicity/genotoxicity. In support of these analyses, data on airborne pollution routinely analysed by local authorities responsible for its control will be collected, referring to the air monitoring units closest to the schools participating in the MAPEC project, in the five cities. Biological and air samples will be repeated in winter and spring, seasons characterised by different type and concentration of air pollutants. Other indoor and outdoor exposures will be investigated using an ad hoc questionnaire administrated to children's parents that includes questions on possible confounders and interaction factors, such as demographic and socioeconomic variables, children's lifestyle, with a focus on diet and physical activity. In conclusion, the whole data set will be analysed to investigate the association between air pollution exposure measures (chemical pollutants and PM toxicity and mutagenicity/genotoxicity) and the early effect biomarkers with the aim of developing a model for calculating the global absolute risk of early biological effects of air pollution and other possible exposure data obtained by the questionnaire.

\section{Sample size}

A total of 1000 children (200 children per town) aged $6-8$ years will be recruited from first grade schools. Two to four schools in each town will be chosen randomly from the list of schools located in areas without adjacent air pollution emission sources. The teachers, school personnel and children's parents will be involved in meetings where members of the research team will explain the project and promote participation. Participation in the study will be voluntary and no incentive will be offered for this.

The sample size of the study has been determined in order to detect statistically significant differences in the early effect biomarkers, that is, primary DNA damage and $\mathrm{MN}$, between children living in towns with high and low air pollution levels. Based on published studies comparing groups at different levels of exposure to airborne mutagens, we expect to observe DNA damage in the comet test, evaluated as an average of $10 \%$ of DNA in comet tail (tail intensity) among participants with higher air pollution exposure levels compared with $7 \%$ in those at a lower exposure levels with an SD of $10 \%$. By enrolling a total of 1000 children, about $40 \%$ of whom are supposed to live in highly polluted towns (Brescia and Turin which are located in the Po Valley), and assuming a log-normal distribution of the biomarkers of early effect, we expect to observe a statistically significant difference between the two groups, with an $\alpha$ error of 0.05 and a power higher than 95\%, using a Student $\mathrm{t}$ test for independent groups at two tails.

Estimating a loss of approximately $20 \%$, because of incomplete or incorrectly compiled questionnaires and/ or an insufficient number of cells collected through biological sampling, an oversampling of participants will be necessary, therefore a total of 1300 children will be recruited.

\section{Inclusion/exclusion criteria}

Only children living in the participating towns will be recruited. Children with severe diseases and those who have been exposed to antineoplastic agents, have undergone radiation therapy or X-rays in the previous 12 months or have a dental prosthetic will be excluded.

\section{Questionnaires}

An ad hoc questionnaire will be designed including items on demographic and socioeconomic variables, exposures to indoor and outdoor air pollution sources, characteristics of the area of residence, parents' smoking at home, BMI, children's respiratory symptoms and diseases, diet, physical activity and other aspects of children's lifestyle. The questionnaire will be based on others used in some international studies on children's respiratory diseases performed in recent decades. ${ }^{51}$

After a pretesting phase, the reliability of the questionnaire will be assessed on about 100 participants using the test-retest method.

The questionnaires will be distributed and collected with the help of the school personnel at two separate times, in winter and late spring (before school closing for summer holidays), from the 1000 children enrolled (2 questionnaires per each child), in the weeks in which environmental and biological samplings will be performed.

For children not providing a filled in questionnaire, further attempts will be made on the next days. As biological samplings will go on for some days, the samples for some of the children absent from school on the established day for taking oral mucosa cells will be retrieved during the whole period of biological sampling.

In order to evaluate the intraindividual variability of biomarkers of early effect, a third environmental and biological sampling will be carried out in the following winter, restricted to 200 children recruited in Brescia.

\section{Collection of environmental samples}

Ultra-fine PM (PM0.5) will be collected near the schools involved in the research. A high-volume air sampler will be located near the schools for $72 \mathrm{~h}$ during the days of biological sampling, both in winter and spring. Furthermore, air and biological samplings will be repeated in the following winter in Brescia. PM0.5 sampling will be carried out using fibreglass filters. All the filters will be weighed for gravimetric determination of PM0.5 and then will undergo organic extraction using sonication to prepare the samples for in vitro mutagenicity/genotoxicity and toxicity tests and chemical analysis.

\section{Chemical analysis}

The chemical analysis of PM0.5 extracts collected in each town for the determination of PAHs and 
nitro-PAHs will be performed at a single laboratory using high pressure liquid chromatography.

\section{Mutagenicity of ultra-fine PM: Ames test}

The mutagenicity of PM0.5 organic extracts collected in all towns will be evaluated using Ames test on bacteria. This test is a short-term mutagenicity test which detects point mutations (base substitution and frameshift mutations) in Salmonella typhimurium strains. ${ }^{52} 53$ The PM0.5 organic extracts, dissolved in a compatible solvent (dimethylsulphoxide; DMSO), will be tested in duplicate at increasing doses with $S$. typhimurium TA100 and TA98 strains, which are generally utilised for environmental studies, ${ }^{18}$ and NR98 and YG1024 strains, which are particularly able to detect nitrocompound. ${ }^{20} 54$ The Ames test will be performed with and without metabolic activation $( \pm S 9)$, adding microsomal enzymes of rat liver to detect direct and indirect mutagens. Plates will be incubated at $37^{\circ} \mathrm{C}$ in the dark for $72 \mathrm{~h}$, after which revertant colonies will be counted and a dose-response curve will be constructed. The net amount of revertants per cubic metre of air equivalent will be evaluated using a linear regression model. The Ames test will be performed at the same laboratory on all samples.

\section{Genotoxicity of ultra-fine PM}

The genotoxicity of PM0.5 organic extracts collected in all towns will be evaluated using comet test and $\mathrm{MN}$ test on human pulmonary A549 cell line.

\section{Comet assay}

The comet assay is a sensitive genotoxicity test which detects primary DNA damage in individual eukaryotic cells. This assay will be carried out on human cells of the respiratory system (A549), which represent the first type of tissue in contact with the airborne pollutants.

The organic extracts of PM0.5 will be transferred to a compatible solvent (DMSO) and tested $\left(24 \mathrm{~h}\right.$ at $37^{\circ} \mathrm{C}$ with $5 \% \mathrm{CO}_{2}$ ) in duplicate at increasing doses using A549 cells. The comet assay will be performed in alkaline conditions $(\mathrm{pH}>13)$ with the protocol to detect oxidative damage using endonuclease (formamidopyrimidine DNA glycosylase) incubation. ${ }^{55} 56$ The comet will be examined using an image analysis system (Comet Assay IV). Results will be expressed as genotoxic parameter per cubic metre of air equivalent. All samples will be analysed at a single laboratory.

\section{Cytokinesis-block MN test}

The genotoxicity of PM0.5 organic extracts collected in the five towns will be evaluated using the cytokinesisblock MN (CBMN) test. The CBMN test will be performed in accordance with the original method by Fenech $^{57}$ on human A549 cells treated in vitro with air extracts. At the end of the in vitro treatment, the medium will be replaced by fresh medium containing cytochalasin B to inhibit cell division after mitosis. The cells will be harvested by trypsinisation and fixed with
Carnoy's reagent, and the cell suspensions will be poured onto precleaned frosted microscope slides. After drying, the slides will be stained, air dried and mounted with Eukitt. Cells will be examined for MN at $400 \times$ magnification according to established criteria. ${ }^{45} \mathrm{MN}$ will be scored in 1000 binucleated cells for each concentration of each repeated experiment. Two independent evaluations will be performed for each sample. All samples will be analysed at a single laboratory.

\section{Toxicity of ultra-fine PM}

Specific potential lung toxicity of organic extracts of PM0.5 will be assessed in vitro on a total of 10 unique samples, obtained by mixing the organic extracts from all the samples individually collected from each town and each season. Cell viability will be assessed by the use of two traditional colorimetric assays: the MTT $(3,(4,5-$ dimethylthiazol-2)2,5 difeniltetrazolium bromide) dyebased assay ${ }^{58}$ and the neutral red dye-based assay. ${ }^{59}$

Organ-specific toxicity/non-genotoxic, tumourpromoting potential of the samples will be evaluated by testing their influence on the gap junctional function (GJIC) of suitable epithelial cells (eg, primary culture of oral mucosae cells or highly junctionally coupled cell line). According to the cell type selected, the scrapeloading technique ${ }^{60}$ or the microinjection/dye-transfer assay ${ }^{61}$ will be used. GJIC was chosen as a biological parameter in our study, since its evaluation still represents one of the most promising and sensitive end points for the mechanistic evaluation of organ-specific toxicity and/or tumour-promoting potential of agents. ${ }^{62} 63$ This particular form of cell-cell communication is, in fact, a unique cell/tissue-specific cellular function, with an unquestioned role in integrated regulation of growth, differentiation processes and functions of multicellular organisms and in tissue homoeostatic control. ${ }^{64}$

Toxicity tests on all PM0.5 extracts will be performed at a single laboratory.

\section{Collection of urban air chemical data}

Data regarding the main air pollutants for which routine measurements are performed by local authorities (Regional Agency for Environmental Protection, ARPA Italian acronym for Agenzia Regionale per la Protezione dell'Ambiente), such as $\mathrm{CO}, \mathrm{NO}_{2}, \mathrm{SO}_{2}$, benzene, $\mathrm{O}_{3}$, PM10 and PM2.5, will be retrieved for each town.

\section{Sampling of oral mucosa cells}

Biological samples will be collected from all the children in winter and in late spring $(1000 \times 2=2000$ samples $)$. Intraindividual variability of early effect biomarkers will be evaluated by collecting further biological samples from 200 children enrolled in Brescia during the following winter. In order to collect BM cells, the children will rinse their mouths twice with mineral water and the mouthwashes will be collected in tubes containing $25 \mathrm{~mL}$ of saline solution $(\mathrm{NaCl} 0.9 \%)$ to obtain 
leucocytes for the comet assay. ${ }^{65}$ Disposable cytobrush cell collectors will then be used to collect exfoliated buccal cells for the MN test by scraping the inside of both cheeks gently and dipping the material into tubes containing $15 \mathrm{~mL}$ of phosphate buffered saline solution.

\section{Early biological effects in children}

Comet assay

An in vivo assessment of primary DNA damage will be performed on leucocytes of the children's BM with the comet assay. ${ }^{65}$ In order to evaluate primary DNA damage caused by exposure to air pollutants, the comet assay in alkaline conditions $(\mathrm{pH}>13)$ will be performed to show single-strand and double-strand breaks and alkali labile sites. ${ }^{55}$ The comet assay will also be performed to detect oxidative damage using endonuclease (formamidopyrimidine DNA glycosylase) incubation. ${ }^{56}$ All the slides will be dried and sent to the same laboratory for microscopic analysis. After rehydration and staining with a DNA intercalating fluorochrome (ie, ethidium bromide or SYBR green), the analysis will be performed using a fluorescence microscope at $400 \times$ magnification, equipped with a digital camera. An average of 100 randomly selected nuclei per participant will be acquired. The images, acquired in TIFF (tagged image file format) format, will be evaluated and the following damage parameters measured for each nucleoid: comet tail length (TL), percentage of detectable DNA in the tail (\%TDNA), tail moment (TM) and Olive TM (OTM).

\section{MN test}

The MN test will be performed on BM cells from the children. For this purpose, the BM scraped cells suspension will be used to prepare the slides according to Thomas et al. ${ }^{66}$ The slides will be stained in light green using the Feulgen method. The dried slides will be mounted with Eukitt and sent to a single laboratory for microscopic analysis. For microscope analysis, the slides will be examined under microscope at $400 \times$ magnification. According to proposed scoring criteria ${ }^{66}{ }^{67}$ before MN frequency calculation, BM cells will be gathered into categories (ie, 'normal' or 'abnormal') on the basis of cytological and nuclear features indicating DNA damage, cytokinetic failure or cell death. MN frequency will be then assessed by two well-trained operators in at least 2000 normal cells per participant.

\section{Risk analysis based on environmental data}

A quantitative estimate of carcinogenic risk will be produced using some risk analysis models, which are based on standard air pollution parameters (PM10, NOx and others) routinely collected by local authorities, and the parameters investigated in this study (PM0.5 content of PAHs and nitro-PAHs). For carcinogenic substances, the risk (R) represents the probability of a rise, with respect to the usual conditions of life, in the number of cases of cancer in a person's lifetime caused by exposure to the substance. The risk analysis will be conducted in accordance with the RBCA (Risk-Based Corrective Action) procedure proposed by the American Society for Testing and Materials (ASTM) and will lead to an estimate of the carcinogenic risk (R) of exposure to polluted air. Afterwards, the model performance in predicting early biological effects in children will be evaluated by comparing the estimates produced by the risk analysis models based on environmental data ('expected') and the actual level of biological effect detected in the children ('observed').

\section{Statistical analysis and construction of a global risk model}

The associations between levels of air pollutants, PM mutagenicity/genotoxicity and early effect biomarkers will be investigated using various types of regression models. Questionnaire data will also be analysed, including both demographic and socioeconomic variables and indoor and outdoor exposure variables. Univariate and multivariate analyses will be performed, considering all the variables of interest and confounding factors. Intraindividual variability of early effect biomarkers will be assessed by comparing the results observed in two samples taken from 200 children in two consecutive winter seasons. A comparison of the results of early effect biomarker tests will be performed between winter and summer seasons, among all towns and between those at higher (Brescia and Turin together) and lower (all the others) levels of PM10 in winter, using the common statistical techniques for the analysis of continuous variables, according to their distribution. The role of interaction factors will be assessed using both stratified analysis and statistical models. The associations between the standard (PM10, NOx, etc) and investigated (PM0.5 content of PAHs and nitro-PAHs) parameters of air pollution and early effect biomarkers will be determined in order to evaluate the air pollution parameters as predictors of biological effect on children. Then a tentative model for calculating the global absolute risk of having early biological effects for air pollution and other variables together (demographic and socioeconomic factors, indoor exposures, physical activity, diet, BMI and others) will be proposed.

\section{ETHICS AND DISSEMINATION}

Participation in the study will be voluntary. Informed consent will be obtained from the children's parents and the children themselves, after an adequate and understandable explanation of the intent of the study, of the possible results and their meaning. Only children with parents' informed consent signed and a complete questionnaire will undergo biological sampling. All the data collected will be treated confidentially in accordance with current Italian legislation on the treatment of sensitive data (privacy law).

An alphanumeric code (6 letter) will be randomly generated to identify both biological samples and questionnaires. In addition to the alphanumeric code, the 
questionnaires will include the child's name in order to enroll only the children whose parents decide to participate in the research and return a written signed consent. Then this section with the child's name will be separated from the rest of the questionnaire and will be kept apart in a closed archive. Only the research staff will be allowed to see the children's personal data.

All data will be analysed in an aggregate and anonymous way for the preparation of scientific reports in which the children will be not identifiable in any way.

Communication and dissemination activities are key issues for achieving the main objective of the MAPEC project. For successful dissemination of study results, multiple target audiences will be identified, each of them needs to be addressed in a different manner, using different media and with different messages. The key message to be conveyed by MAPEC will be indications for addressing individual interventions and community policies to protect children from the health effects of air pollutants. A dissemination plan will be designed taking into account the specific language of interest and communication channel of possible stakeholders: health authorities, scientific community, teachers, children, parents, etc.

Scientific meetings and workshops will be periodically organised to show preliminary and final results, which will be presented at national and international conferences and then published in scientific journals. Also community, environmental and health authorities will be involved. MAPEC participatory integrated assessment is an object-oriented approach with the strong engagement of local, national and European Union stakeholders. Furthermore, the results will be communicated to Public Health Agencies, and to the Mayor of each town for supporting health policy decisions. Annual meetings will be organised with representatives of national public health institutions and we will organise an international workshop at the end of the project.

Finally, the general public will be involved. Presentation of the project objectives, information and results will need to be tailored to a public or non-scientific audience in order to ensure effective communication. Lay science articles in local and national newspapers will be produced with the aim to reach out to and create a bridge between scientific and public audiences. Press conferences will be organised with local and national mass media to present the project before all workshops. Moreover, a MAPEC newsletter will be developed and distributed to different stakeholders and a project website will be developed.

Local Public Health Authorities and teachers will be involved in developing information and educational packages, containing lesson plans, enrichment activities and ideas for encouraging students to adopt healthy lifestyles, which can be used by other schools throughout the country.

\section{Author affiliations}

${ }^{1}$ Department of Medical and Surgical Specialties, Radiological Science and Public Health, University of Brescia, Brescia, Italy
${ }^{2}$ Department of Biological and Environmental Science and Technology, University of Salento, Lecce, Italy

${ }^{3}$ Department of Pharmaceutical Sciences, University of Perugia, Perugia, Italy ${ }^{4}$ Department of Biology, University of Pisa, Pisa, Italy

${ }^{5}$ Department of Public Health and Pediatrics, University of Torino, Torino, Italy

${ }^{6}$ Comune di Brescia, Brescia, Italy

${ }^{7}$ Centro Servizi Multisettoriale e Tecnologico-CSMT Gestione S.c.a.r.I.,

Brescia, Italy

${ }^{8}$ Department of Translational Research, N.T.M.S., University of Pisa, Pisa, Italy

${ }^{9}$ Department of Clinical and Experimental Sciences, University of Brescia,

Brescia, Italy

${ }^{10}$ Department of Economics, University of Brescia, Brescia, Italy

Collaborators Components of the MAPEC_LIFE Study Group: Sara Compiani, Francesco Donato, Andrea Festa, Gaia Claudia Viviana Viola, Ilaria Zerbini, Department of Medical and Surgical Specialties, Radiological Science and Public Health, University of Brescia, 11 Viale Europa, 25123 Brescia, Italy;

Marcello Guido, Adele Idolo, Francesca Serio, Maria Rosaria Tumolo, Tiziano

Verri, Department of Biological and Environmental Science and Technology, University of Salento, 165 Via Provinciale Lecce-Monteroni, 73100 Lecce, Italy; Luca Dominici, Cristina Fatigoni, Sara Levorato, Manola Peverini, Samuele Vannini, Department of Pharmaceutical Sciences, University of Perugia, Via del Giochetto, 06122 Perugia, Italy; Beatrice Bruni, Elisa Caponi, Gabriele Donzelli, Department of Biology, University of Pisa, 13 Via Ghini, 56126 Pisa, Italy; Giorgio Gilli, Cristina Pignata, Department of Public Health and Pediatrics, University of Torino, 94 Piazza Polonia, 10126 Torino, Italy; Silvia Bonizzoni, Camilla Furia, Comune di Brescia, 1 Piazza Repubblica, 25100 Brescia, Italy; Francesco Braga, Roberta Codenotti, Paolo Colombi, Daniela Lini, Evelyn Mario, Centro Servizi Multisettoriale e TecnologicoCSMT Gestione S.c.a.r.l., 45 Via Branze, 25123 Brescia, Italy;

Contributors All the authors contributed to this work and have taken part in the academic discussion for writing the study protocol, drafting the article and revising it. They have all approved the final version. DF, EC and UG gave substantial contributions to conception and design, acquisition of data, or analysis and interpretation of data; $A D D, A C, M R M, A B, S M$ and $E C$ have draft the article or revised it critically for important intellectual content; $M M, S B$, LC, FB, MVi, MVe, TS, RML, TG, BC, CZ, GM and RL gave final approval of the version to be published.

Funding This work has been funded by the European Commission Directorate General Environment in the LIFE+ programme for 2012, Environment Policy and Governance (grant number: LIFE12 ENV/IT/000614).

\section{Competing interests None.}

Ethics approval The project has been approved by the local Ethics Committee (Comitato Etico Provinciale della Provincia di Brescia) on 15 January 2014 and the local Health Authorities of each town involved in the study..

Provenance and peer review Not commissioned; peer reviewed for ethical and funding approval prior to submission.

Open Access This is an Open Access article distributed in accordance with the Creative Commons Attribution Non Commercial (CC BY-NC 4.0) license, which permits others to distribute, remix, adapt, build upon this work noncommercially, and license their derivative works on different terms, provided the original work is properly cited and the use is non-commercial. See: http:// creativecommons.org/licenses/by-nc/4.0/

\section{REFERENCES}

1. EEA. Air quality in Europe-2013 report. European Environment Agency, 2013.

2. WHO. Particulate matter air pollution: how it harms health. World Health Organisation, 2005

3. Anderson JO, Thundiyil JG, Stolbach A. Clearing the air: a review of the effects of particulate matter air pollution on human health. $J$ Med Toxicol 2012;8:166-75.

4. Raaschou-Nielsen O, Andersen ZJ, Beelen R, et al. Air pollution and lung cancer incidence in 17 European cohorts: prospective analyses from the European Study of Cohorts for Air Pollution Effects (ESCAPE). Lancet Oncol 2013;14:813-22. 
5. Shah ASV, Langrish JP, Nair $\mathrm{H}$, et al. Global association of air pollution and heart failure: a systematic review and meta-analysis. Lancet 2013;382:1039-48.

6. Silva RA, West JJ, Zhang Y, et al. Global premature mortality due to anthropogenic outdoor air pollution and the contribution of past climate change. Environ Res Lett 2013;8:034005

7. WHO. Review of evidence on health aspects of air pollutionREVIHAAP Project. First results. WHO Regional Office for Europe, World Health Organisation, 2013.

8. Beelen R, Raaschou-Nielsen O, Stafoggia M, et al. Effects of long-term exposure to air pollution on natural-cause mortality: an analysis of 22 European cohorts within the multicentre ESCAPE project. Lancet 2014;383:785-95.

9. Cesaroni G, Forastiere F, Stafoggia M, et al. Long term exposure to ambient air pollution and incidence of acute coronary events: prospective cohort study and meta-analysis in 11 European cohorts from the ESCAPE Project. BMJ 2014;348:f7412.

10. Puett RC, Hart JE, Schwartz J, et al. Are particulate matter exposures associated with risk of type 2 diabetes? Environ Health Perspect 2011:119:384-9.

11. Sørensen $M$, Autrup $H$, Møller $P$, et al. Linking exposure to environmental pollutants with biological effects. Mutat Res 2003;544:255-71.

12. Lewtas J. Air pollution combustion emissions: characterization of causative agents and mechanisms associated with cancer, reproductive, and cardiovascular effects. Mutat Res 2007;636:95-133.

13. Bonetta S, Gianotti V, Bonetta S, et al. DNA damage in A549 cells exposed to different extracts of PM2.5 from industrial, urban and highway sites. Chemosphere 2009;77:1030-4.

14. Claxton LD, Woodall GM Jr. A review of the mutagenicity and rodent carcinogenicity of ambient air. Mutat Res 2007;636:36-94.

15. Møller $\mathrm{P}$, Folkmann JK, Forchhammer $\mathrm{L}$, et al. Air pollution, oxidative damage to DNA, and carcinogenesis. Cancer Lett 2008;266:84-97.

16. Monarca S, Crebelli R, Feretti D, et al. Mutagens and carcinogens in size-classified air particulates of a northern Italian town. Sci Total Environ 1997;205:137-44.

17. Monarca S, Feretti D, Zanardini A, et al. Monitoring of mutagens in urban air samples. Mutat Res 1999;426:189-92.

18. Claxton LD, Matthews PP, Warren SH. The genotoxicity of ambient outdoor air, a review: Salmonella mutagenicity. Mutat Res 2004;567:347-99.

19. Coronas MV, Pereira TS, Rocha JA, et al. Genetic biomonitoring of an urban population exposed to mutagenic airborne pollutants. Environ Int 2009;35:1023-9.

20. Traversi D, Degan R, De Marco R, et al. Mutagenic properties of PM2.5 urban pollution in the northern Italy: the nitro-compounds contribution. Environ Int 2009;35:905-10.

21. de Brito KC, de Lemos CT, Rocha JA, et al. Comparative genotoxicity of airborne particulate matter (PM2.5) using Salmonella plants and mammalian cells. Ecotoxicol Environ Saf 2013;94:14-20.

22. de Rainho CR, Machado Corrêa S, Mazzei JL, et al. Genotoxicity of polycyclic aromatic hydrocarbons and nitro-derived in respirable airborne particulate matter collected from urban areas of Rio de Janeiro (Brazil). Biomed Res Int 2013;765352.

23. WHO. Air quality guidelines. Global update 2005. Particulate matter, ozone, nitrogen dioxide and sulfur dioxide. Copenhagen, Denmark: World Health Organization, Regional Office for Europe, 2006.

24. Carpenter DO, Arcaro K, Spink DC. Understanding the human health effects of chemical mixtures. Environ Health Perspect 2002;110:25-42.

25. Bonassi S, Znaor A, Norppa H, et al. Chromosomal aberrations and risk of cancer in humans: an epidemiologic perspective. Cytogenet Genome Res 2004;104:376-82.

26. Bonassi S, Znaor A, Ceppi M, et al. An increased micronucleus frequency in peripheral blood lymphocytes predicts the risk of cancer in humans. Carcinogenesis 2007;28:625-31.

27. Bonassi S, El-Zein R, Bolognesi $\mathrm{C}$, et al. Micronuclei frequency in peripheral blood lymphocytes and cancer risk: evidence from human studies. Mutagenesis 2011;26:93-100.

28. Neri M, Fucic A, Knudsen LE, et al. Micronuclei frequency in children exposed to environmental mutagens: a review. Mutat Res 2003;544:243-54

29. Neri M, Bonassi S, Knudsen LE, et al. Children's exposure to environmental pollutants and biomarkers of genetic damage. I. Overview and critical issues. Mutat Res 2006;612:1-13.

30. Neri M, Ugolini D, Bonassi S, et al. Children's exposure to environmental pollutants and biomarkers of genetic damage. II. Results of a comprehensive literature search and meta-analysis. Mutat Res 2006;612:14-39.
31. Holland N, Fucic A, Merlo DF, et al. Micronuclei in neonates and children: effects of environmental, genetic, demographic and disease variables. Mutagenesis 2011;26:51-6.

32. Lahiri T, Roy S, Basu C, et al. Air pollution in Calcutta elicits adverse pulmonary reaction in children. Indian $J$ Med Res 2000;112:21-6.

33. Montero R, Serrano L, Dávila V, et al. Metabolic polymorphisms and the micronucleus frequency in buccal epithelium of adolescents living in an urban environment. Environ Mol Mutagen 2003;42:216-22.

34. Chen C, Arjomandi M, Qin H, et al. Cytogenetic damage in buccal epithelia and peripheral lymphocytes of young healthy individuals exposed to ozone. Mutagenesis 2006;21:131-7.

35. Huen K, Gunn L, Duramad P, et al. Application of a geographic information system to explore associations between air pollution and micronucleus frequencies in African American children and adults. Environ Mol Mutagen 2006;47:236-46.

36. Sisenando HA, Batistuzzo de Medeiros SR, Artaxo P, et al. Micronucleus frequency in children exposed to biomass burning in the Brazilian Legal Amazon region: a control case study. BMC Oral Health 2012;12:6.

37. Ceretti E, Feretti D, Viola GCV, et al. DNA damage in buccal mucosa cells of pre-school children exposed to high levels of urban air pollutants. PLoS ONE 2014;9:e96524.

38. Landrigan PJ, Kimmel CA, Correa A, et al. Children's health and the environment: public health issues and challenges for risk assessment. Environ Health Perspect 2004;112:257-65.

39. WHO. Effects of air pollution on children's health and development. Copenhagen, Denmark: World Health Organization Regional Office for Europe, 2005

40. WHO. Children's health and the environment in Europe: a baseline assessment. Copenhagen, Denmark: World Health Organization Regional Office for Europe, 2007.

41. Bateson TF, Schwartz J. Children's response to air pollutants J Toxicol Environ Health A 2008;71:238-43.

42. Grigg J. Particulate matter exposure in children: relevance to chronic obstructive pulmonary disease. Proc Am Thorac Soc 2009;6:564-9.

43. ERS. Air quality and health. Lausanne, Switzerland: European Respiratory Society, 2010.

44. Wild CP, Kleinjans J. Children and increased susceptibility to environmental carcinogens: evidence or empathy? Cancer Epidemiol Biomarkers Prev 2003;2:1389-94.

45. Kirsch-Volders M, Plas G, Elhajouji A, et al. The in vitro MN assay in 2011: origin and fate, biological significance, protocols, high throughput methodologies and toxicological relevance. Arch Toxicol 2011;85:873-99.

46. Fairbairn DW, Olive PL, O'Neill KL, et al. The Comet assay: a comprehensive review. Mutat Res 1995;339:37-59.

47. Burlinson B, Tice RR, Speit G, et al. Fourth International Workgroup on Genotoxicity testing: results of the in vivo comet assay workgroup. Mutat Res 2007;627:31-5

48. Collins AR, Oscoz AA, Brunborg G, et al. The comet assay: topical issues. Mutagenesis 2008;23:143-51.

49. Dhawan A, Anderson D. The comet assay in toxicology. RSC Publishing, 2009.

50. ISPRA. Stato dell'Ambiente 45/13. Qualità dell'ambiente urbano. IX Rapporto. Roma: Istituto Superiore per la Protezione e la Ricerca Ambientale, 2013

51. Migliore E, Berti G, Galassi C, et al. Respiratory symptoms in children living near busy roads and their relationship to vehicular traffic: results of an Italian multicentre study (SIDRIA 2). BMC Environ Health 2009;8:27.

52. Maron DM, Ames BN. Revised methods for the Salmonella mutagenicity test. Mutat Res 1983;113:173-215.

53. APHA. Standard method for the examination of water and wastewater. 20th edn. Washington DC: American Public Health Association/American Water Works Association/Water Environmental Federation, 1998.

54. Watanabe M, Sofuni T, Nohmi T. Comparison of sensitivity of Salmonella typhimurium strains YG1024 and YG1012 for detecting the mutagenicity of aromatic ammines and nitroarenes. Mutat Res 1993;301:7-12.

55. Singh NP, McCoy MT, Tice RR, et al. A simple technique for quantitation of low levels of DNA damage in individual cells. Exp Cell Res 1988;175:184-91.

56. Collins AR, Duthie SJ, Dobson VL. Direct enzymic detection of endogenous oxidative base damage in human lymphocyte DNA. Carcinogenesis 1993;14:1733-735.

57. Fenech $\mathrm{M}$. The in vitro micronucleus technique. Mutat Res 200;455:81-95. 
58. Bernard-Beaubois $\mathrm{K}$, Hecquet $\mathrm{C}$, Hayem $\mathrm{G}$, et al. In vitro study of cytotoxicity of quinolones on rabbit tenocytes. Cell Biol Toxicol 1988;14:283-92.

59. Borenfreud E, Puerner JA. A simple quantitative procedure using monolayer cultures for cytotoxicity assays (HTD/NR-90). J Tissue Cult Methods 1984;9:7-9.

60. El-Fouly MH, Trosko JE, Chang CC. Scrape-loading and dye transfer. A rapid and simple technique to study gap junctional intercellular communication. Exp Cell Res 1987:168:422-30.

61. Mazzoleni G, Telò P, Camplani A, et al. Influence of the herbicide Linuron on growth rate and gap-junctional intercellular communication of cultured endothelial cells. J Environ Pathol Toxicol Oncol 1994;13:1-10.

62. Swierenga SH, Yamasaki H. Performance of tests for cell transformation and gap-junction intercellular communication for detecting

non-genotoxic carcinogenic activity. In: Mechanism of Carcinogenesis in Risk Identification. IARC Scientific Publications No. 116. Lyon: International Agency for Research on Cancer, 1992:165-193.
63. Mazzoleni G, Camplani A, Telò P, et al. Effect of tumor-promoting and anti-promoting chemicals on the viability and junctional coupling of human HeLa cells transfected with DNAs coding for various murine connexin proteins. Comp Biochem Physiol C Pharmacol Toxicol Endocrinol 1996; 113:247-56.

64. Bruzzone R, White TW, Paul DL Connections with connexins: the molecular basis of direct intercellular signaling. Eur J Biochem 1996;38:1-27.

65. Osswald K, Mittas A, Glei M, et al. New revival of an old biomarker: characterisation of buccal cells and determination of genetic damage in the isolated fraction of viable leucocytes. Mutat Res 2003:544:321-9.

66. Thomas $\mathrm{P}$, Holland $\mathrm{N}$, Bolognesi $\mathrm{C}$, et al. Buccal micronucleus cytome assay. Nat Protoc 2009;4:825-37.

67. Tolbert PE, Shy CM, Allen JW. Micronuclei and other nuclear anomalies in buccal smears: methods development. Mutat Res 1992;271:69-77. 